\title{
The Mechanical Properties of Low-Carbon Low-Alloy Bainitic Steels*
}

\author{
By Yasuya OHMORI,** Hiroo OHTANI,** and Tatsuro KUNITAKE**
}

\section{Synopsis}

The relationship between the morphology and the mechanical properties in the isothermally transformed low-carbon low-alloy bainite has been investigated in comparison with those of tempered martensite.

The strength of bainite increased with lowering the transformation temperature which reduced the thickness of the ferrite laths. As the decrease in the transformation temperature also reduced the unit crack path for cleavage fracture, the toughness in the impact test was improved. In the martensitebainite duplex structure formed isothermally below $M s$, higher zensile strength was achieved without reducing toughness, and this structure exhibited better impact properties than the martensite tempered at lower temperatures to produce the equivalent strength. The toughness of this duplex structure, however, was not so good as that of the bainite-martensite duplex structure formed by the continuous cooling transformation in the vicinity of upper critical cooling rate.

\section{Introduction}

In the previous paper, ${ }^{11}$ the bainite in low-carbon low-alloy steels was classified into three different types: i.e., the bainite $I$, which comprised the laths of carbidefree ferrite with the untransformed austenite layers between them (they decomposed into martensite during the subsequent quenching), the bainite $I I$, which consisted of the ferrite laths with cementite layers between them, and the bainite $I I I$, which exhibited the same $\langle 111\rangle_{\alpha}\{110\}_{\alpha}$ habit as upper bainite but contained the cementite platelets in a similar array to lower bainite. It can, therefore, be expected that such a morphological difference has a significant effect on the strength and toughness of steels.

In fact, the effect of microstructure on the toughness has been the subject of numerous investigations for some time, and it is now widely accepted that the microstructural change from pearlite to martensite through bainite improves the impact properties. ${ }^{2,3)}$ For the bainite of the steel containing $0.34 \% \mathrm{C}$, Nakajima and Araki ${ }^{4}$ confirmed that lowering the isothermal transformation temperature produced a sharp decrease of the impact transition temperature with refining the cleavage facet.

Although the reason for such lowering of the transition temperature was commonly believed to arise from the fine grain size, the recent investigations ${ }^{5-8)}$ have revealed that the toughness is more closely related to the size of the fracture facet which is not directly con- nected to the individual grain. In tempered martensite, Inoue et al. ${ }^{6)}$ showed that such a fracture facet consisted of a bunch of ferrite laths with similar orientations. Terasaki and Ohtani ${ }^{7)}$ developed this idea and found that the facet comprised the ferrite grains whose $\{100\}_{\alpha}$ cleavage planes did not incline more than $10^{\circ}$ to one another, and thus it involved more than those of nearly the same orientations.

Recently Edwards ${ }^{3)}$ found that the lower bainitemartensite duplex structure in an $0.35 \% \mathrm{C}-3 \% \mathrm{Ni}-\mathrm{Cr}-$ Mo steel exhibited much better toughness than an individual bainite or martensitic structure. For the continuous cooling transformation, a similar result for the bainite $I I I-$ martensite duplex structure in some lowcarbon low-alloy steels was also obtained by Ohtani et al. ${ }^{8)}$ and they demonstrated that the improvement of toughness was due to the formation of bainite laths which separated an austenite grain into several pieces, hence reducing the size of the fracture facet.

Therefore the aim of the present work is to examine the strength and toughness of the bainite in low-carbon low-alloy steels with a particular emphasis on the transformation temperature and the results will be discussed in relation to those in tempered martensite.

\section{Experimental Procedure}

\section{Materials and Heat Treatment}

The chemical compositions of the two steels selected for the present investigation are given in Table 1. They were received as hot-rolled plates of $7 \mathrm{~mm}$ thick and were machined into the shape of oblong strip of $7 \times 15 \times 70 \mathrm{~mm}^{3}$.

In order to produce bainitic structure, the heat treatment was carried out using the T.T.T. diagrams determined previously. ${ }^{1)}$ They were austenitized at $1200^{\circ} \mathrm{C}$ for $15 \mathrm{~min}$ in an argon filled furnace and quenched into a $\mathrm{Pb}$-bath held at the required decomposition temperature. After the isothermal transformation, they were quenched into iced water. The details of the heat treatment are shown in Figs. 1 and 2 schematically.

To compare the properties of bainitic structure with

Table 1. The chemical compositions of the steels used (wt \%)

\begin{tabular}{c|cccccccccrrrrr}
\hline Steel & C & Si & Mn & P & S & Cu & Ni & Cr & Mo \\
\hline 7 & 0.12 & 0.30 & 0.84 & 0.004 & 0.005 & 0.30 & 1.11 & 0.53 & 0.47 & 0.03 & 0.030 \\
5 & 0.22 & 0.24 & 0.83 & 0.007 & 0.011 & 0.30 & 1.06 & 0.54 & 0.51 & -0.029 \\
\hline
\end{tabular}

* Presented at the 81st ISIJ Meeting, April, 1971, in Tokyo. Manuscript received August $11,1971$.

** Central Research Laboratories, Sumitomo Metal Industries, Ltd., Nishinagasu-hondori, Amagasaki 660. 


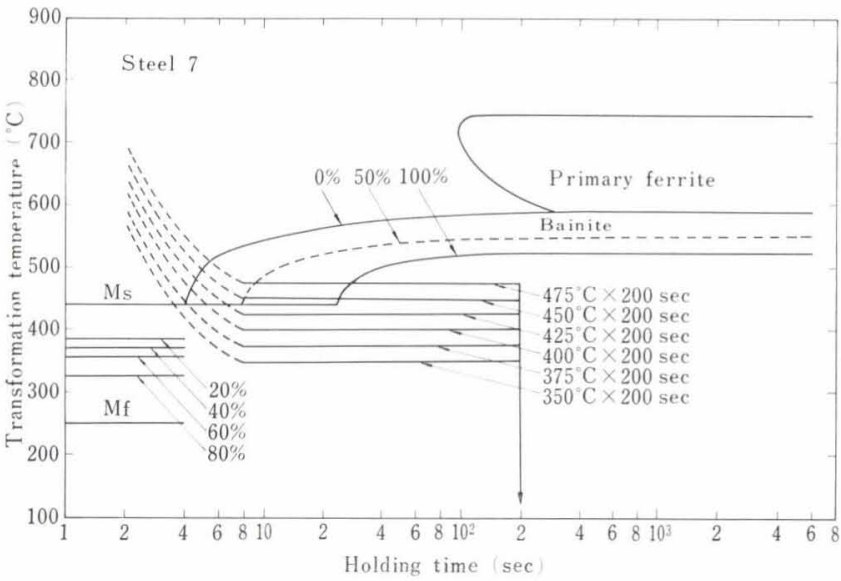

Fig. 1. The T.T.T. diagram and the details of the heat treatments for the steel 7

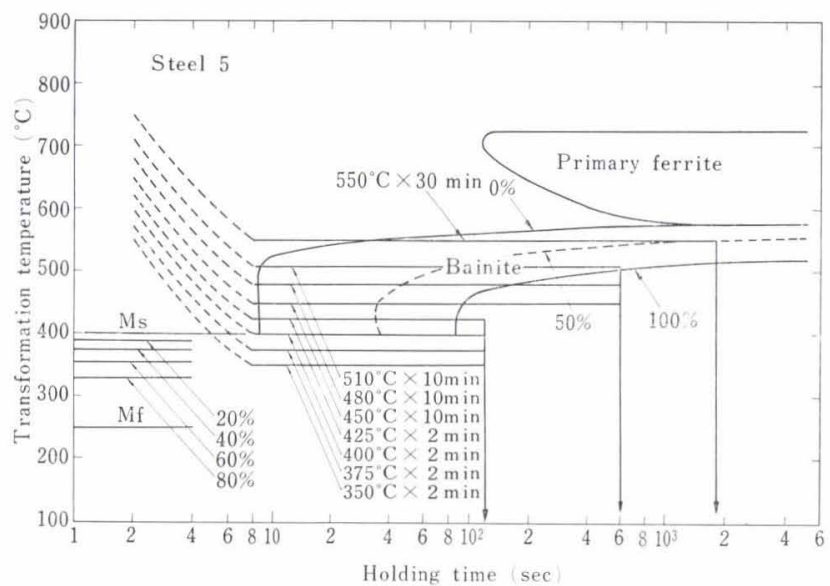

Fig. 2. The T.T.T. diagram and the details of the heat treatments for the steel 5

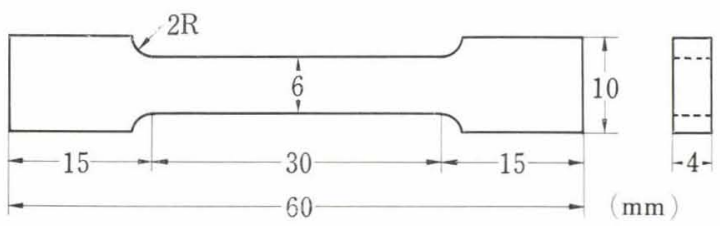

Fig. 3. The shape of the tensile specimens

those of tempered martensite, the specimens of the steel 5 were austenitized at $1200^{\circ} \mathrm{C}$ for $15 \mathrm{~min}$ and quenched into iced brine to produce fully martensitic structure. Tempering was carried out for $1 \mathrm{hr}$ in the temperature range between $200^{\circ}$ and $650^{\circ} \mathrm{C}$.

\section{Mechanical Tests}

The impact transition temperatures were determined by the use of sub-size $2 \mathrm{~mm} \mathrm{~V}$-notch Charpy specimens whose thickness was $5 \mathrm{~mm}$. The shape of the tensile specimens is shown in Fig. 3 and the test was conducted at the strain rate of $6.7 \% / \mathrm{min}$ at room temperature. The hardness of the tempered martensite was also measured.

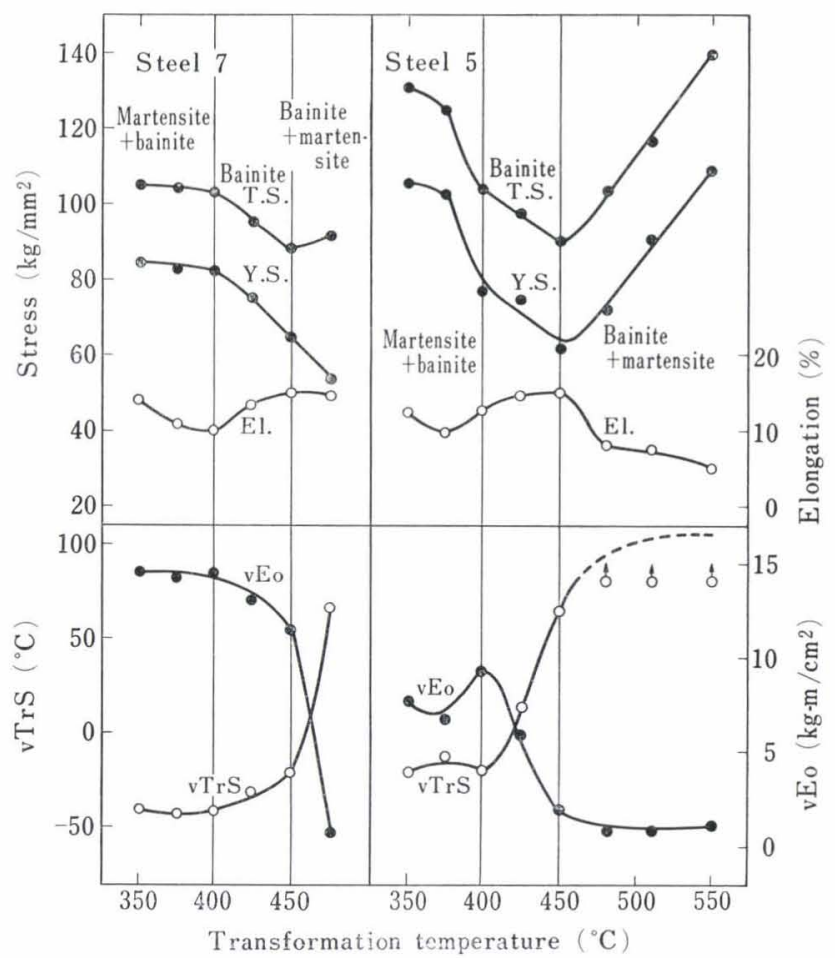

Fig. 4. The effect of the isothermal transformation temperatures on the mechanical properties of the steels 7 and 5

\section{Microstructural Observation and Fractography}

The microstructure was examined by means of both optical and electron microscopies. The electrolyte for the thin foil preparation was a chromic-phosphric acid solution, and the foils were observed in a Hitachi HU-200 electron microscope operated at $200 \mathrm{kV}$. The brittle fracture surfaces of the Charpy impact specimens were examined in a JEOL JSM-2 scanning electron microscope.

\section{Experimental Results}

\section{Mechanical Properties}

\section{Bainite}

Both the Charpy and the tensile properties of the steels 7 and 5 in relation to the isothermal transformation temperature are shown in Fig. 4. Above $450^{\circ} \mathrm{C}$, the tensile strength of the steel 5 increased as the transformation temperature was raised, while the toughness showed a sharp decrease. This can be explained in terms of the existence of the martensite which was formed from the untransformed austenite during the subsequent quenching. ${ }^{*}$ In the temperature range between $450^{\circ}$ and $400^{\circ} \mathrm{C}$, both the strength and the impact transition temperature were improved with decreasing transformation temperature, and it is interesting to note that the steel 7 exhibited exactly the same strength as the steel 5, the $0.1 \%$ difference in carbon content having no effect on the strength in this range. Below $400^{\circ} \mathrm{C}$, although the strength of the

* According to the T.T.T. diagram (Fig. 2) no martensite could be expected for $475^{\circ} \mathrm{C}$ transformation, but in the present case the decomposition of the austenite in the steels 5 and 7 was not completed as shown in the microstructural observation. 
steel 5 remarkably increased as the temperature was lowered, that of the steel 7 did not exhibit any significant change. The toughness of each steel at these temperatures was almost the same as that of $400^{\circ} \mathrm{C}$.

\section{Tempered Martensite}

In Fig. 5, the mechanical properties of the steel 5 are plotted against tempering temperature. The strength decreased with increasing tempering temperature in a usual manner, but retarded softening can be observed at $350^{\circ}$ and $550^{\circ} \mathrm{C}$. It can also be seen that the retardation is slightly different for either the ultimate tensile strength or the yield strength. The impact properties, on the other hand, exhibited a quite different behaviour and the embrittlement occurred in the temperature range between $250^{\circ}$ and $400^{\circ} \mathrm{C}$. This is so-called $500^{\circ} \mathrm{F}$-embrittlement which is probably due to the cementite precipitation. ${ }^{9)}$ The toughness was improved by higher temperature tempering. It should, however, be noted that this improvement was retarded at $550^{\circ} \mathrm{C}$. In order to reveal

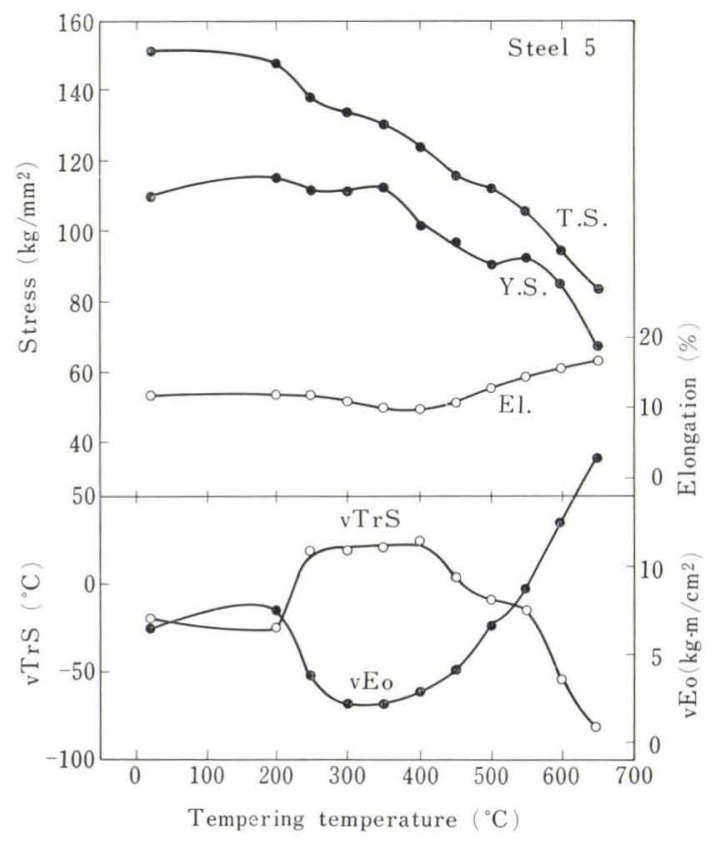

Fig. 5. The effect of the tempering temperature on the mechanical properties of the martensite (the steel 5)

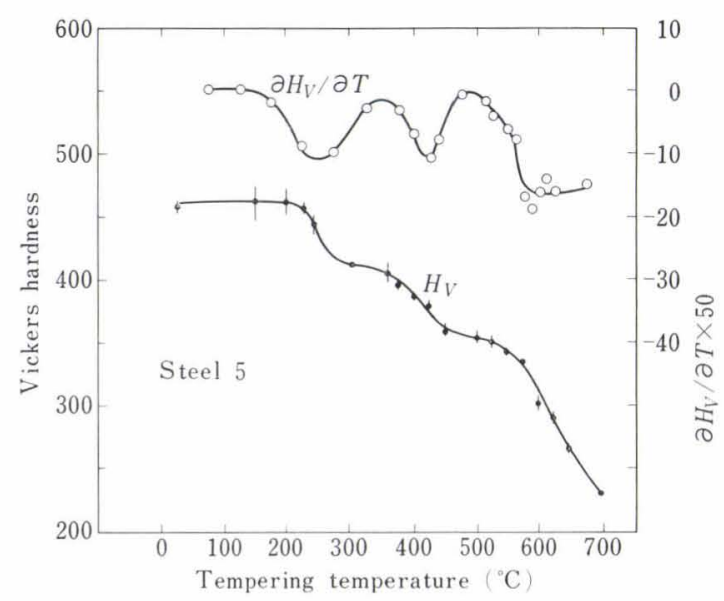

Fig. 6. The effect of the tempering temperature on the hardness of the martensite such a complicated tempering behaviour, the hardness of the tempered martensite was measured and the results are given in Fig. 6 with their temperature derivatives. It can be seen that the derivative of the hardness showed remarkable increase in the temperature ranges between $250^{\circ}$ and $420^{\circ} \mathrm{C}$, and between $430^{\circ}$ and $600^{\circ} \mathrm{C}$.

\section{Microstructures}

\section{Bainite}

When the specimens were transformed isothermally at the temperatures above $500^{\circ} \mathrm{C}$, the transformation was incomplete and acicular carbide-free ferrite formed as the sheaves of parallel laths, the untransformed austenite decomposing into martensite during the following quenching (Photo. 1). This structure had been classified as the bainite $I .{ }^{1)}$ Decreasing the transformation temperature to some $475^{\circ} \mathrm{C}$, a typical upper bainite, i.e., the bainite $I I,{ }^{1)}$ which consisted of the parallel ferrite laths with cementite layers between them, formed as shown in Photos. 2 (a) and (b), but the bainite $I$ was still observed to exist (Photos. 3 (a) and (b)). Therefore strictly speaking, the transformation was still incomplete even at this temperature, and this contradicts with the previously determined T.T.T. diagrams ${ }^{1)}$ shown in Figs. 1 and 2. An explanation for this could be made in terms of the size effect of the specimens heat-treated, i.e., the specimen, which was cooled slowly to the isothermal transformation temperature, produced a considerable amount of carbidefree bainite with carbon enrichment in austenite, thus the untransformed austenite being stabilized.

In the temperature range between $450^{\circ}$ and $400^{\circ} \mathrm{C}$, the structure was typical of the bainite $I I I,{ }^{1)}$ where the ferrite lath has a $\langle 111\rangle_{\alpha}\{110\}_{\alpha}$ habit but the morphology of cementite is similar to that in lower bainite as shown in Photo. 4 (a). The dark field image using a cementite reflection, the selected area electron diffraction pattern, and its schematic representation are shown in Photos. 4 (b), (c), and (d) respectively. It can be seen in this pattern that the cementite was related to ferrite with the Isaicev orientation relationship: ${ }^{10)}$

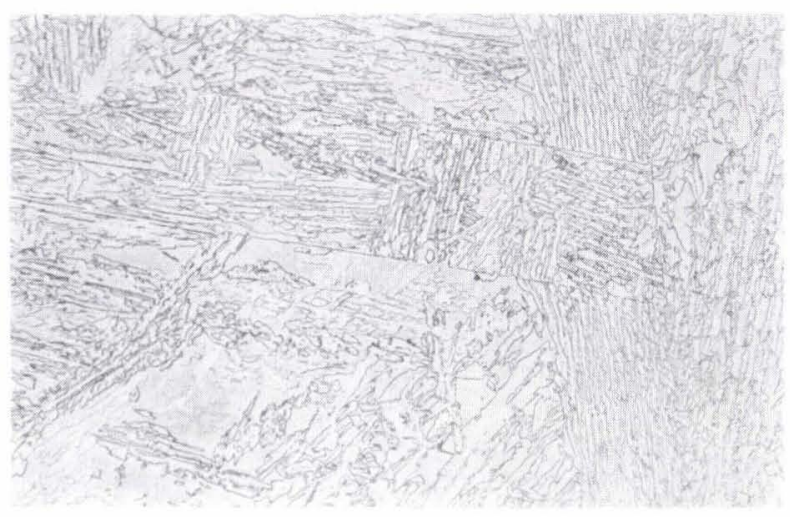

Photo. 1. The carbide-free bainite laths (the bainite $I$ ) formed by the isothermal transformation at $510^{\circ} \mathrm{C}$ in the steel $5(\times 500)\left(\times \frac{3}{4}\right)$ 

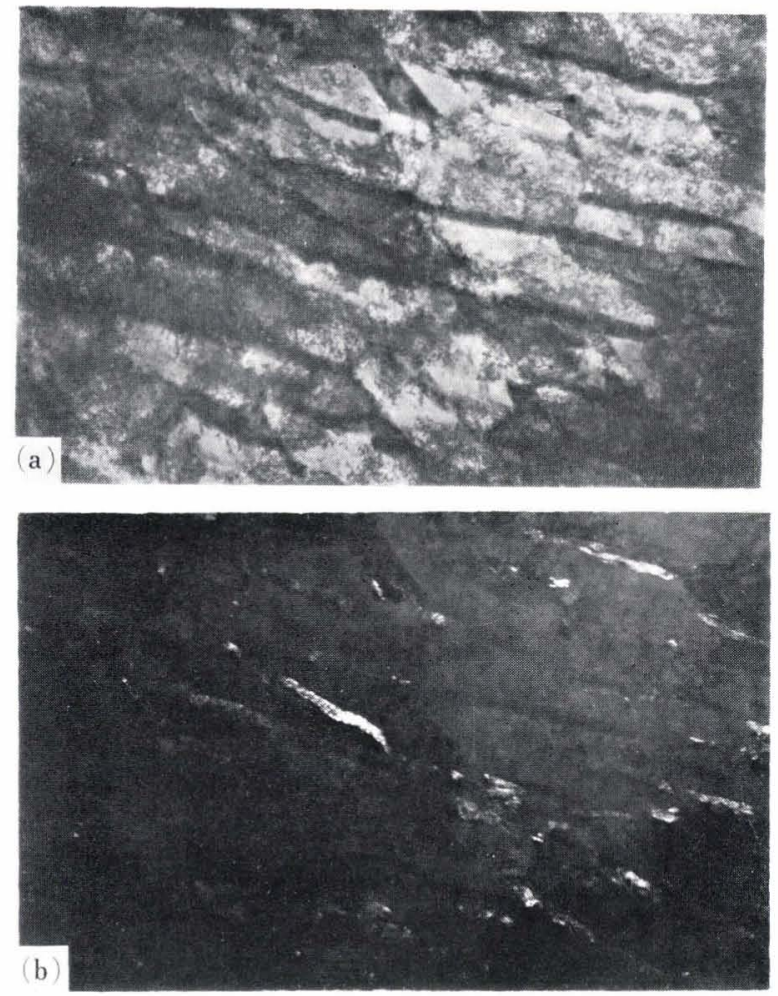

Photo. 2. Typical upper bainite (the bainite $I I$ ) formed at $475 \mathrm{C}$ in the steel 7

(a) The bright field image $(\times 20000)\left(\times \frac{1}{2}\right)$

(b) The dark field image using a cementite reflection $(\times 20000)\left(\times \frac{1}{2}\right)$
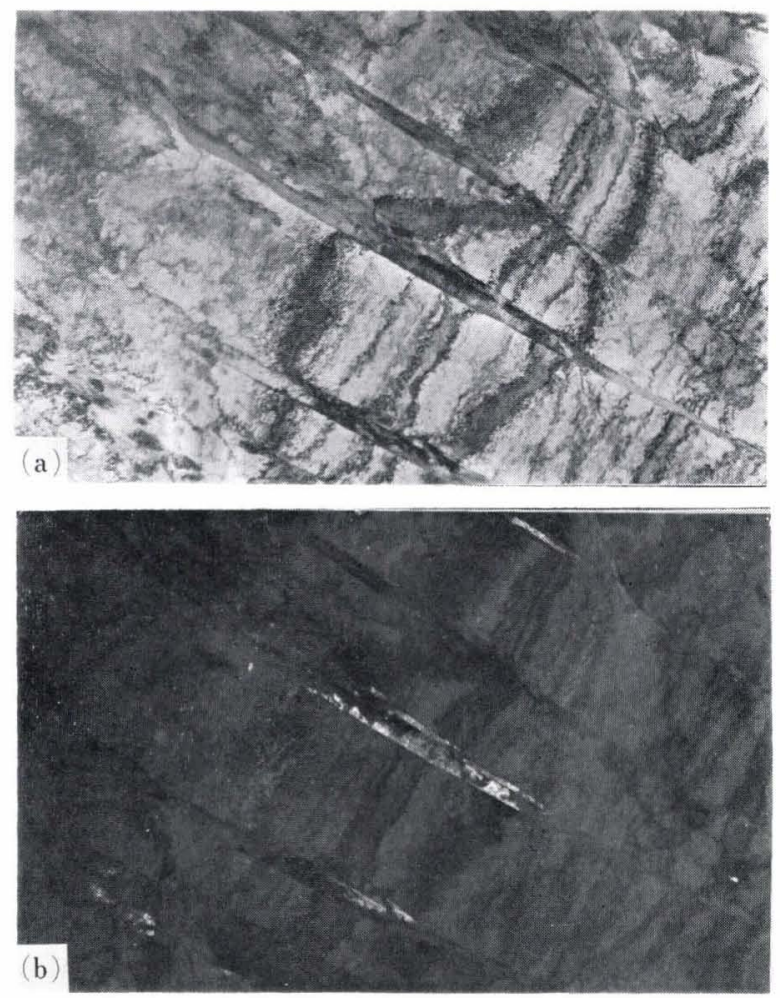

Photo. 3. The bainite $I$ formed at the temperature as low as $475^{\circ} \mathrm{C}$

(a) The bright field image $(\times 20000)\left(\times \frac{1}{2}\right)$

(b) The dark field image using a martensite reflection which arose from the layers between the bainite laths $(\times 20000)\left(\times \frac{1}{2}\right)$
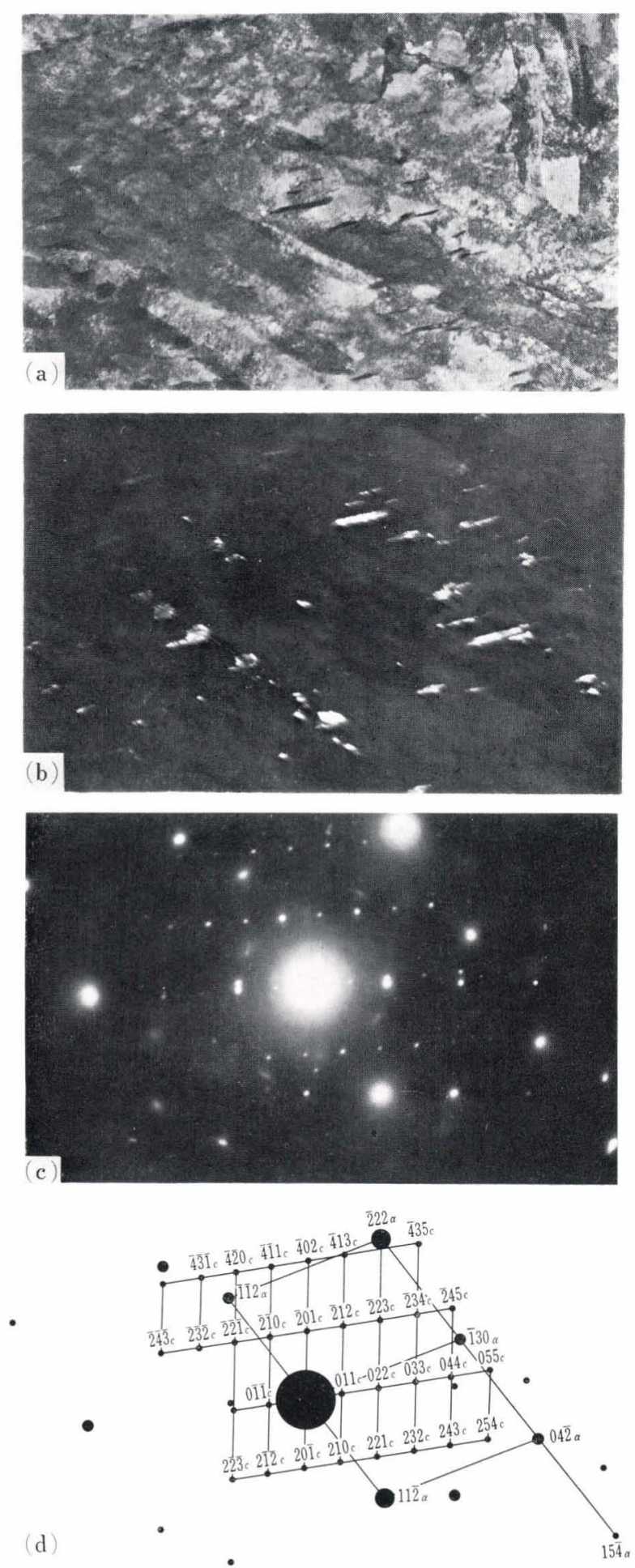

Photo. 4. The bainite $I I I$ formed at $450^{\circ} \mathrm{C}$ in the steel 7 (a) The bright field image $(\times 20000)\left(\times \frac{1}{2}\right)$

(b) The dark field image using a cementite reflection $(\times 20000)\left(\times \frac{1}{2}\right)$

(c) The selected area electron diffraction pattern (d) Its schematic representation

$$
\begin{aligned}
& (010)_{c} / /(\overline{1} 1 \overline{1})_{\alpha} \\
& (\overline{1} 03)_{c} / /(011)_{\alpha}
\end{aligned}
$$

However this does not preclude it being that of $\mathrm{Ba}$ garyatskii, ${ }^{11)}$ because these two relationships are too close to distinguish in this orientation. Although the 


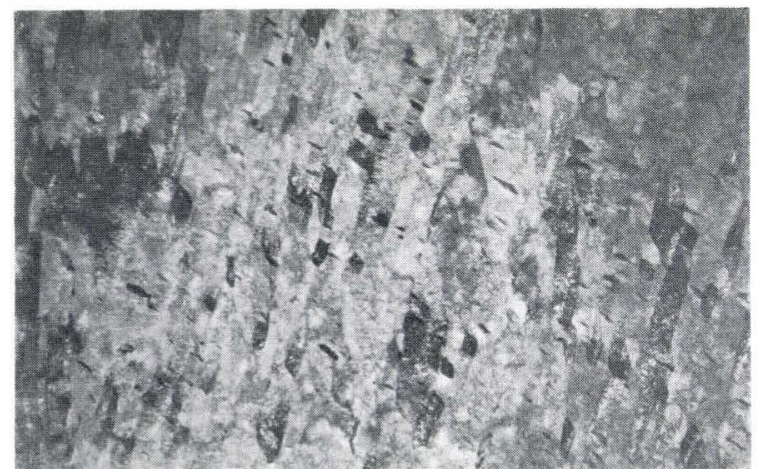

Photo. 5. The bunch of bainite laths in the martensite bainite duplex structure $(\times 20000)\left(\times \frac{1}{2}\right)$

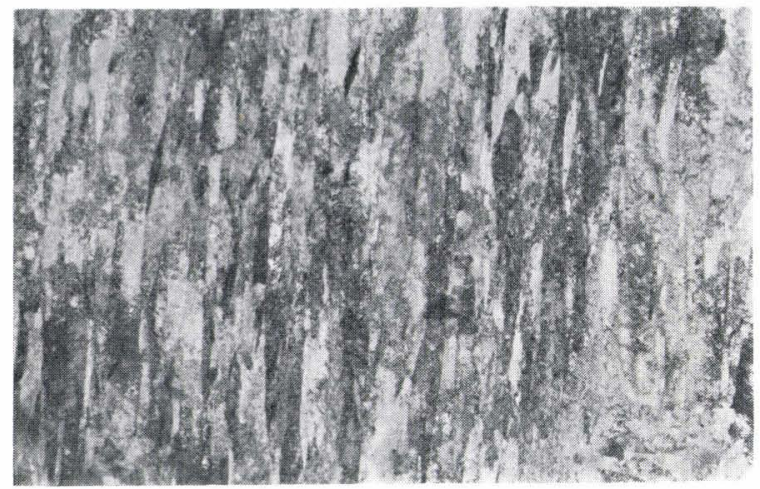

Photo. 6. The bunch of martensite laths in the martensite bainite duplex structure $(\times 20000)\left(\times \frac{1}{2}\right)$

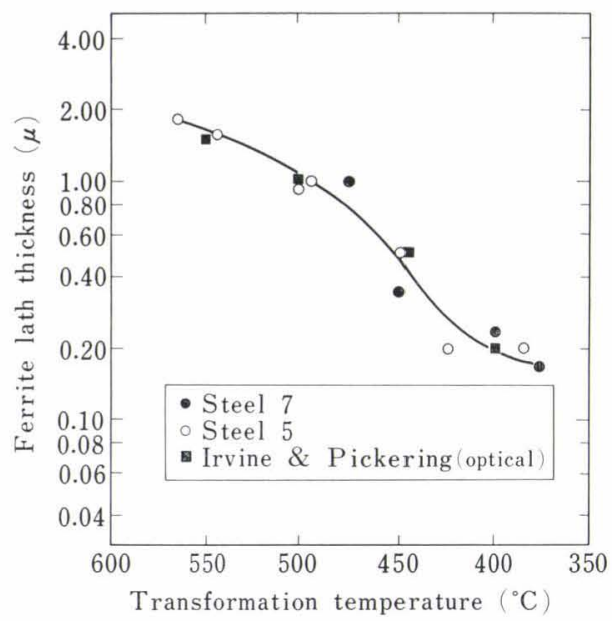

Fig. 7. The effect of the isothermal transformation temperature on the thickness of bainite laths

Ms point for the steel 7 is above $400^{\circ} \mathrm{C}$ (see Fig. 1), no martensite was observed to form at $400^{\circ} \mathrm{C}$. This also could arise out of the size effect of the specimens heat-treated.

Decreasing the transformation temperature into the range between $400^{\circ} \mathrm{C}$ and $\mathrm{Mf}$, the martensite-bainite duplex structure was obtained. This comprised the individual bunches of either bainite or martensite laths as shown in Photo. 5 or Photo. 6 respectively.

The thickness of such bainite laths was measured using the micrographs and is shown in Fig. 7. The
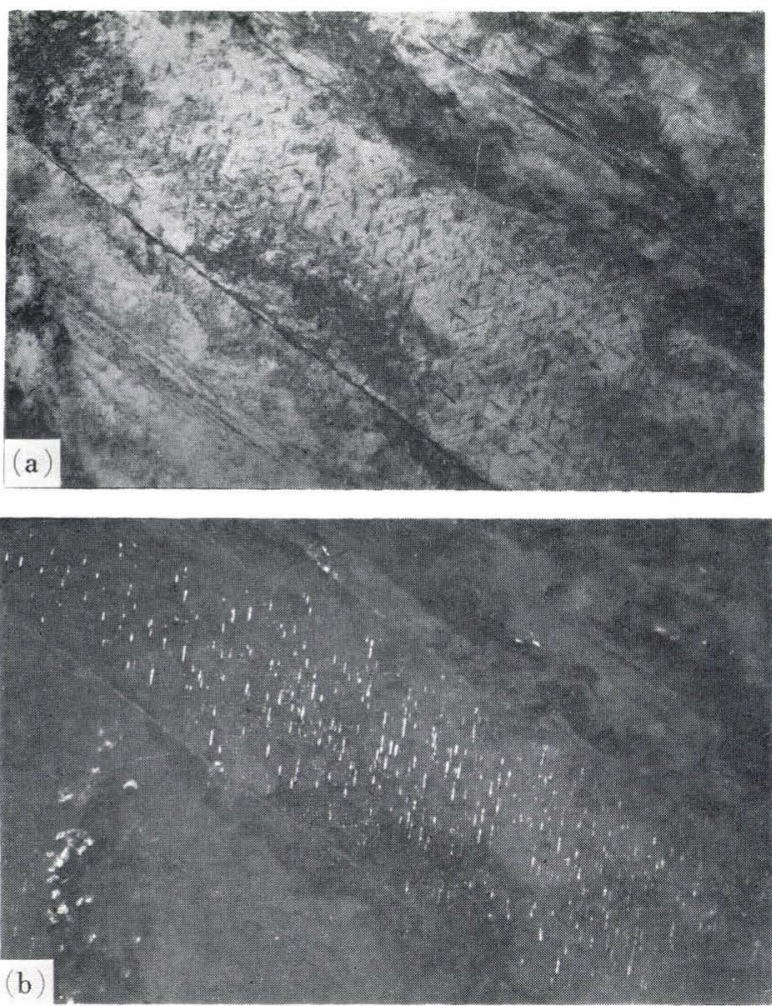

Photo. 7. Widmanstätten array of the carbide laths in the martensite of the steel 5

(a) The bright field image $(\times 20000)\left(\times \frac{1}{2}\right)$

(b) The dark field image using a carbide reflection $(\times 20000)\left(\times \frac{1}{2}\right)$
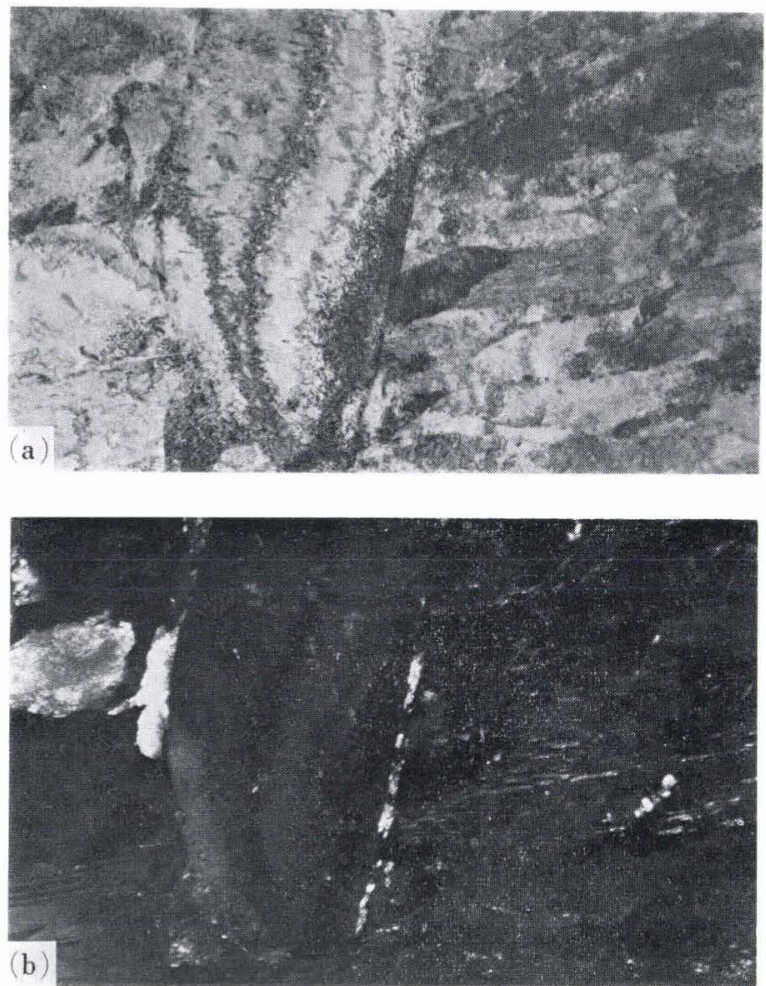

Photo. 8. The grain boundary precipitation of carbides in the martensite tempered at $400^{\circ} \mathrm{C}$ for $1 \mathrm{hr}$

(a) The bright field image $(\times 40000)\left(\times \frac{1}{2}\right)$

(b) The dark field image using a carbide reflection $(\times 40000)\left(\times \frac{1}{2}\right)$ 
results by Irvine and Pickering ${ }^{12)}$ for low-carbon lowalloy high strength steels are also superimposed on this figure.

\section{Tempered Martensite}

The martensite of the steel 5 consisted of bundles of laths which contained fine precipitates in a Widmanstätten array as shown in Photo. 7. Unfortunately the reflections from these autotempered carbides were too diffuse for the structural identification, but they had a lath-like morphology with the $\langle 111\rangle_{\alpha}\{110\}_{\alpha}$ habit. Tempering in the range between $200^{\circ}$ and $300^{\circ} \mathrm{C}$ produced no substantial change of the Widmanstätten carbides. On tempering at temperatures above $300^{\circ} \mathrm{C}$, fine and almost continuous carbide particles formed at the martensite lath and the previous austenite grain boundaries as shown in Photos. 8 (a) and (b). The spheroidization of carbide eventually occurred after tempering at temperatures above $450^{\circ} \mathrm{C}$.

\section{Fractography}
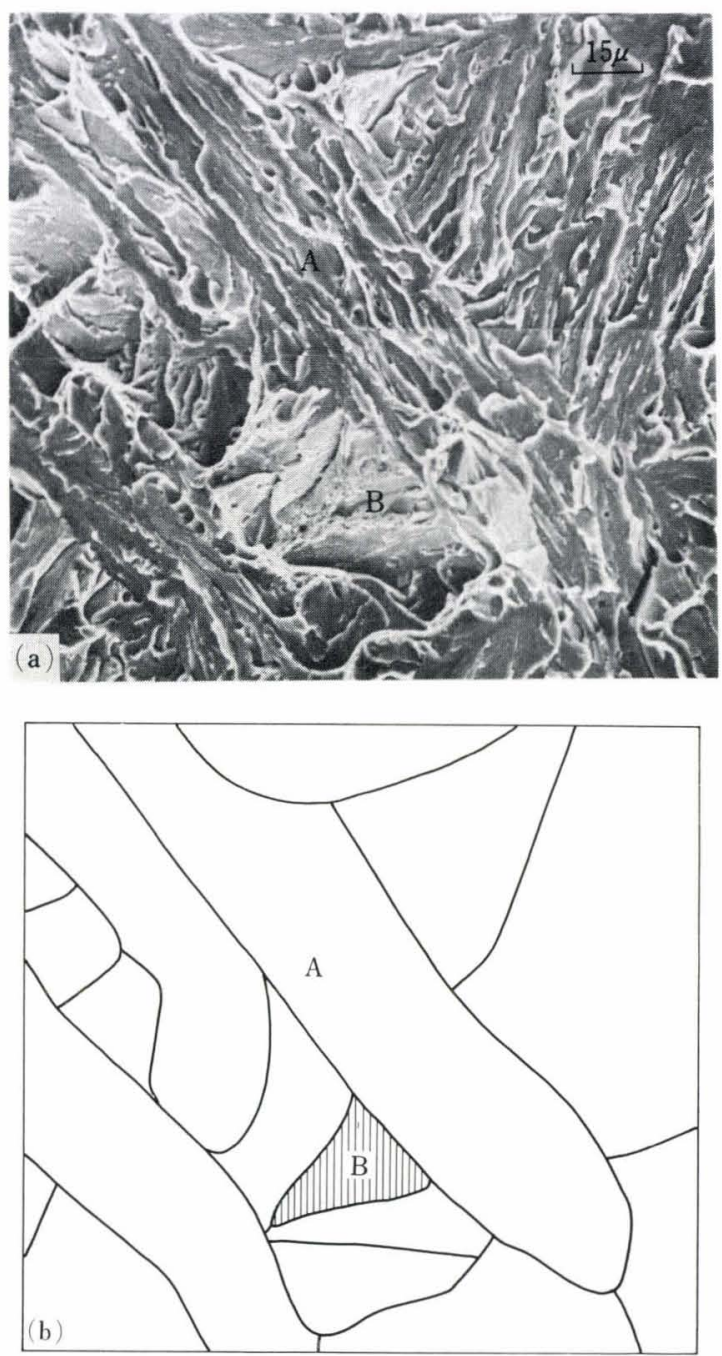

Photo. 9. Brittle fracture surface of the steel 5 isothermally transformed at $450^{\circ} \mathrm{C}$ for $10 \mathrm{~min}$ (broken at $-40^{\circ} \mathrm{C}$ )

(a) The scanning electron micrograph

(b) The schematic illustration of the facet interfaces (A: cleavage facet, B: ductile area)
The brittle fracture surfaces of the Charpy impact specimens were examined by means of scanning electron microscopy. The results for the bainitic structures formed at $450^{\circ}$ and $400^{\circ} \mathrm{C}$ are in Photos. 9 (a) and 10 (a). It can be seen that the majority of the fracture surfaces consisted of the cleavage facets with river markings within them (Photo. 9 (a) A, Photo. 10 (a) B). At the boundaries separating the individual cleavage facets, the thin ductile areas were observed, and such boundaries are shown in Photos. 9 (b) and 10 (b) schematically. Occasionally, the small ductile areas were also observed to form among the cleavage facets as shown in Photo. 9 (a) B, and Photo. 10 (a) A. The size of the cleavage facet decreased with lowering the isothermal transformation temperature (compare Photo. 9 with Photo. 10).

The fracture surface of the martensite tempered at $400^{\circ} \mathrm{C}$ for $1 \mathrm{hr}$ is shown in Photo. 11 and exhibits a typical of intergranular fracture.
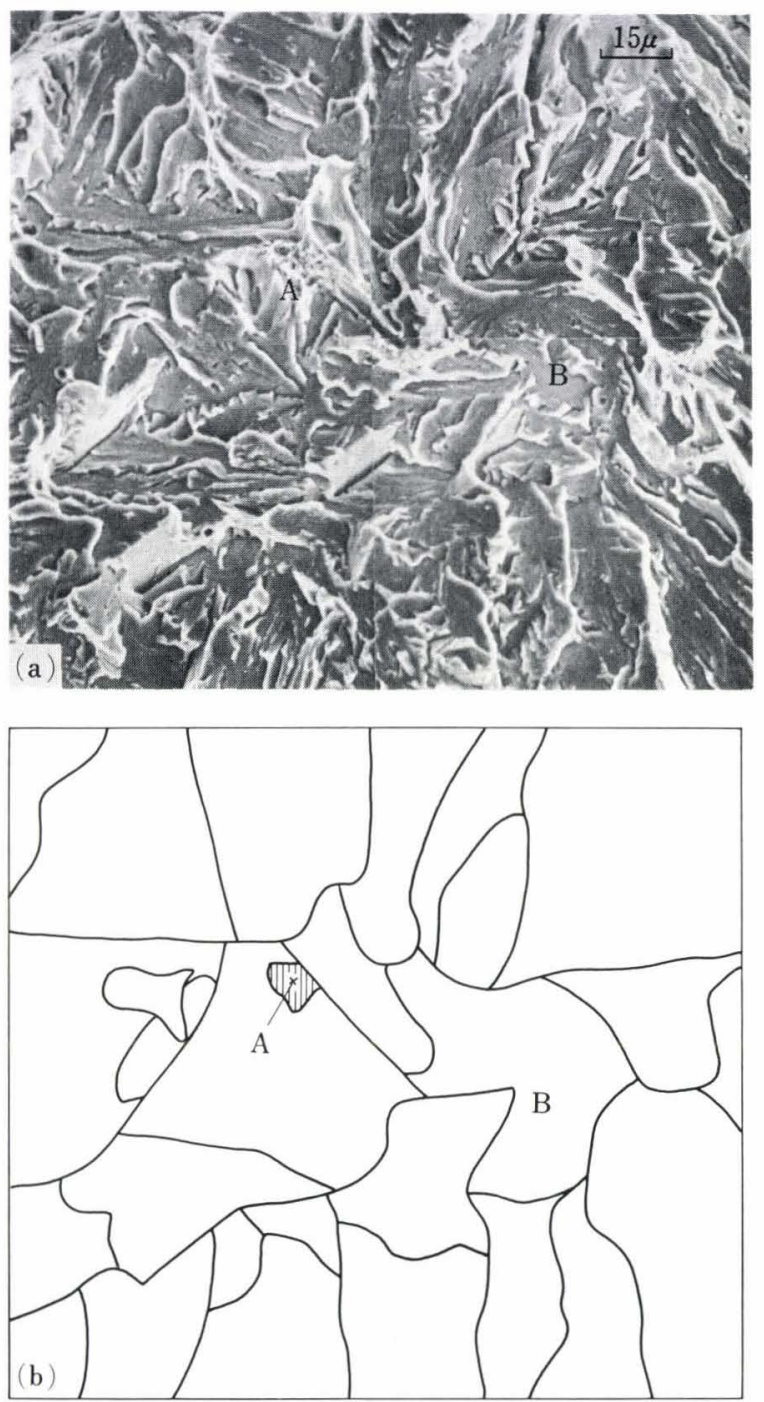

Photo. 10. Brittle fracture surface of the steel 5 isothermally transformed at $400^{\circ} \mathrm{C}$ for $2 \mathrm{~min}$ (broken at $-60^{\circ} \mathrm{C}$ )

(a) The scanning electron micrograph

(b) The schematic illustration of the facet interfaces (A: ductile area, B: cleavage facet) 


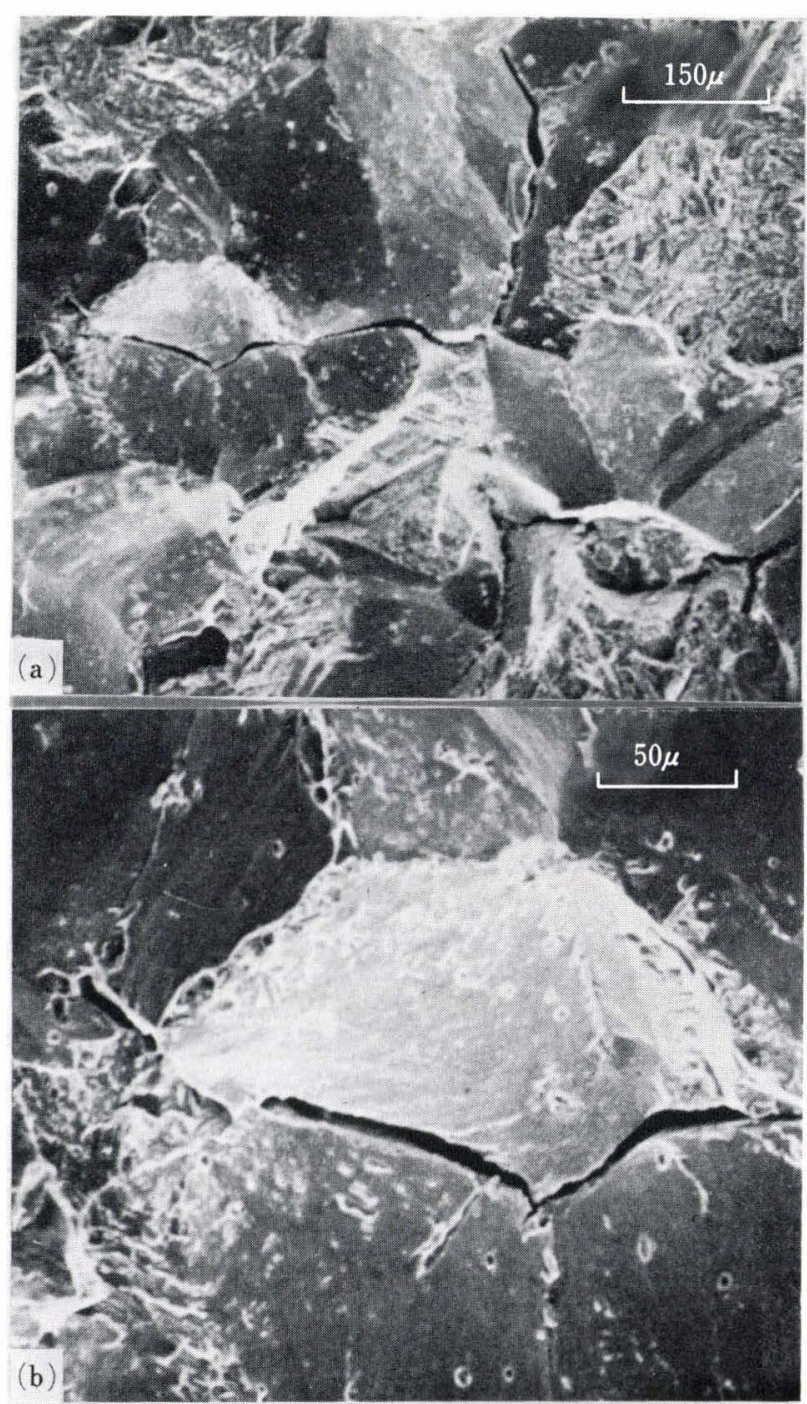

Photo. 11. A typical intergranular fracture surface in the martensite tempered at $400^{\circ} \mathrm{C}$ for $1 \mathrm{hr}$ (broken at $-80^{\circ} \mathrm{C}$ )

(a) Lower magnification

(b) Higher magnification as can be seen in Fig. 4. Such an improvement of toughness has been explained in terms of the fine grain size. ${ }^{14)}$ This is, of course, qualitatively true in the present work, however the recent investigations ${ }^{5-8}$ ) demonstrated that the size of fracture facets was much larger than that of the individual grains. In the present case, the size of the cleavage facets (for the bainite formed in the range between $400^{\circ}$ and $450^{\circ} \mathrm{C}$ ) is in the range between about 20 and $50 \mu$ as shown in Photos. 10 and 9, whereas the thickness of the individual laths is between 0.2 and $0.5 \mu$. Hence the individual ferrite lath could not correspond to the fracture facet and it seems reasonable to introduce the concept of the unit crack path ${ }^{7)}$ for the size of the fracture facet. It should be noted that the unit crack path became finer as the transformation temperature was lowered. This indicates that the number of the sheaves of the bainite laths which lay in almost same orientations should increase with decreasing transformation temperature. Hehemann and Troiano ${ }^{15)}$ pointed out that the number of bainite nuclei above the critical size to grow was limited at higher transformation temperatures, and Aaronson and Wells ${ }^{16}$ ) showed that such bainite laths formed as sheaves in a sympathetic fashion. Consequently the size of the bunch of laths decreases with lowering the temperature and this is in good agreement with the present result.

The effect of the carbon content on the Charpy transition temperature can be seen in Fig. 4 and this suggests that the cementite platelets in bainite induced the cleavage cracks in a certain manner. This is also in keeping with the observation by McMahon and Cohen ${ }^{17)}$ where the majority of the ferrite microcracks in the polycrystalline iron originated at carbide cracks. The shelf energy (the absorbed energy in the ductile range) increased with decreasing carbon content. For this point, Gurland and Plateau ${ }^{18}$ ) showed that the ductility exhibited a sharp decrease with increasing the volume fraction of dispersed particles. The explanation for this has been made in terms of the number of dimples per unit area.

\section{Martensite-Bainite Duplex Structure}

In the temperature range between $400^{\circ} \mathrm{C}$ and $\mathrm{Mf}$, martensite-bainite duplex structure was observed to form, and the strength of this structure showed a remarkable increase with increasing carbon content. This can be explained in terms of the strength of martensite which largely depends on the carbon concentration. ${ }^{19)}$ Although Irvine et al..$^{20)}$ attributed the majority of this hardness increase in low-carbon martensite to the amount of carbon atoms in solid solution, this mechanism seems to be questionable in the present case, because the martensite was almost fully tempered. Namely the martensite formed during quenching to the isothermal decomposition temperature, and after the specimen reached this temperature, the reaction occurred as the bainite transformation. Thus the martensite in the duplex structure was completely tempered, carbon atoms being precipitated in the form of Widmanstätten carbides. Therefore the 
variation of the strength with carbon content could arise out of either the fine dispersion of the Widmanstätten carbides within the martensite laths or the amount of the bainite which was produced by slack quench.

Whereas it is interesting to note that the impact transition temperature neither decreased nor increased with lowering the decomposition temperature from $400^{\circ}$ to $350^{\circ} \mathrm{C}$, and stayed almost constant even in the fully martensitic structure. This suggests that the unit crack path ${ }^{7)}$ does not change in the structure which was formed by the isothermal decomposition at the temperatures below $400^{\circ} \mathrm{C}$, and agrees with the observation where both the bainite and the martensite laths formed as the individual bunches separately and the thickness of the laths did not vary in this temperature range (about $0.2 \mu$ ).

However, for the continuous cooling transformation, much better toughness than that of martensite was achieved in the bainite $I I I$-martensite duplex structure. ${ }^{8)}$ This indicates that the order of the transformation is quite important for the improvement of toughness. Namely, though 10 to $20 \%$ bainite III formation prior to the martensite formation largely improved the toughness, 70 to $80 \%$ martensite formation before the bainite formation did not produce a significant effect on toughness. On this point, it has been already pointed out ${ }^{8)}$ that the bainite, which preceded the martensite formation, separated an austenite grain into several pieces, thus reducing the unit crack path. This can also explain the present result where the bainite, which formed after the formation of considerable amount of martensite, cannot refine the austenite grain any more.

\section{Tempered Martensite}

During the tempering of martensite, the slight retardation of the softening was observed to occur in the temperature ranges between $250^{\circ}$ and $420^{\circ} \mathrm{C}$, and between $430^{\circ}$ and $600^{\circ} \mathrm{C}$. The former was accompanied by a sharp decrease in toughness. Grossmann initially believed that such an embrittlement arose from the decomposition of the retained austenite, ${ }^{21)}$ but later Lement et al. ${ }^{9)}$ showed that it was due to the cementite precipitation. The present results, where the carbide films formed at both the austenite grain and the martensite lath boundaries and the brittle fracture propagated along these boundaries, can be explained by this idea. ${ }^{9)}$ During the tempering of high carbon martensite, however, it was recently confirmed that the monoclinic $\chi$-carbide, ${ }^{22,23)}$ which gave almost the same diffraction pattern as cementite in many orientations, formed in this temperature range. ${ }^{24)}$ Therefore, it seems difficult to determine whether $\chi$-carbide or cementite is responsible for the $500^{\circ} \mathrm{F}$-embrittlement.

The latter retardation of the softening at higher temperature is typical of the secondary hardening due to the alloy carbide formation. In this case, the precipitation of $\mathrm{Mo}_{2} \mathrm{C}$ probably induced this hardening. ${ }^{25)}$

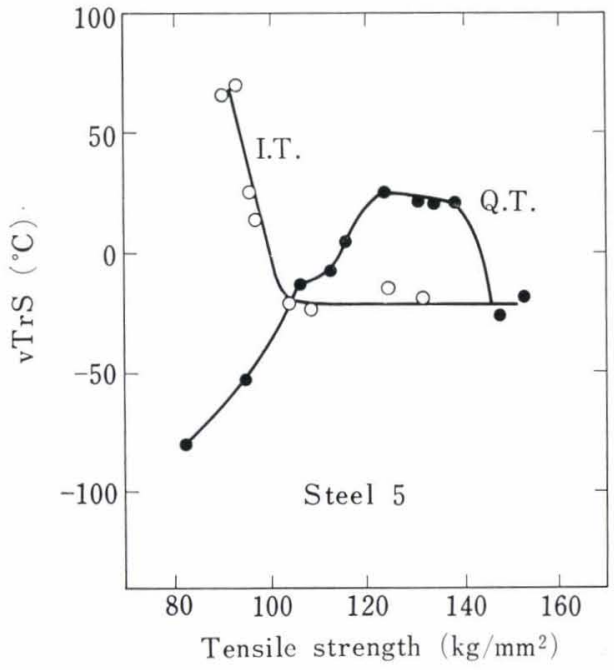

Fig. 8. The relationship between the strength and toughness

\section{Comparison of Bainite and Tempered Martensite}

In order to make comparison of the mechanical properties of bainite with those of tempered martensite, the toughness was plotted against the strength as shown in Fig. 8. At the ultimate tensile strength lower than about $100 \mathrm{~kg} / \mathrm{mm}^{2}$, the better toughness can be achieved by the usual quench and temper treatment. However, in higher strength levels, it can be seen that the isothermal treatment gives lower transition temperature. This can be explained in terms of the $500^{\circ} \mathrm{F}$-embrittlement in tempered martensite as described above. Therefore, it would be of interest to compare the toughness of bainite or martensitebainite duplex structure with that of the tempered martensite which does not exhibit the $500^{\circ} \mathrm{F}$-embrittlement.

\section{Conclusions}

The mechanical properties of the isothermally transformed bainitic structure were examined in relation to those of tempered martensite and the following results were obtained:

(1) On decreasing the transformation temperature from $450^{\circ}$ to $400^{\circ} \mathrm{C}$, the impact transition temperature was lowered with increasing the strength. This can be explained in terms of both the ferrite lath thickness and the unit crack path. ${ }^{\text {) }}$

(2) The strength of bainite is little affected by the carbon content.

(3) The martensite-bainite duplex structure which was formed isothermally below Ms produced a significant strength increase in the higher carbon steel without reducing the impact properties.

(4) By tempering the martensite in the temperature range between $250^{\circ}$ and $450^{\circ} \mathrm{C}$, the quite large embrittlement $\left(500^{\circ} \mathrm{F}\right.$-embrittlement) was observed to occur and the majority of the brittle fracture surfaces exhibited a typical of intergranular fracture.

(5) In order to obtain the higher strength than about $100 \mathrm{~kg} / \mathrm{mm}^{2}$, the isothermal treatment is more suitable than the tempering of martensite, because of the $500^{\circ} \mathrm{F}$-embrittlement occurred in the tempered 
martensite.

\section{Acknowledgements}

The authors wish to thank Dr. M. Sumitomo, Managing Director of the Central Research Laboratories, Sumitomo Metal Industries, Ltd., for permission to publish this paper, and Dr. E. Miyoshi for the encouragements during the progress of the work.

Sincere thanks are due to Dr. T. Shiraiwa and Dr. F. Terasaki for providing the facility of a transmission electron microscopy and especially for their kind preparation of the scanning electron micrographs.

Thanks are also due to Mr. T. Yamamoto and Mr. M. Sata for their skilful technical assistance.

\section{REFERENCES}

1) Y. Ohmori, H. Ohtani, and T. Kunitake: Trans. ISIJ, 11 (1971), 95 .

2) B. Cina and P. Jubb: JISI, 189 (1959), 329.

3) D. P. Edwards: JISI, 207 (1969), 1494.

4) H. Nakajima and T. Araki: Tetsu-to-Hagané, 57 (1971), S110.

5) A. M. Turkalo: Trans. AIME, 218 (1960), 24.

6) T. Inoue, S. Matsuda, Y. Okayama, and K. Aoki: Trans. JIM, 11 (1970), 36
7) F. Terasaki and H. Ohtani: Tetsu-to-Hagané, 58 (1972), 293; Trans. ISIJ, 12 (1972), 45.

8) H. Ohtani, F. Terasaki, and T. Kunitake, Tetsu-to-Hagané, 58 (1972), 434; Trans. ISIJ, 12 (1972), 118, in this issue.

9) B. S. Lement, B. L. Averbach, and M. Cohen: Trans. ASM, 46 (1954), 851.

10) I. V. Isaichev: Zhur. Techn. Fiziki, 17 (1947), 835.

11) A. Bagaryatskii: Dokl. Akad. Nauk SSSR, 73 (1950), 1161.

12) K. J. Irvine and F. B. Pickering, JISI, 188 (1958), 101.

13) Y. Ohmori and R. W. K. Honeycombe: Proc. Int. Con. Sci. Tech. Iron and Steel (Tokyo) (1970).

14) A. H. Cottrell: Trans. AIME, 212 (1958), 192.

15) R. F. Hehemann and A. R. Troiano: Trans. AIME, 200 (1954), 1272.

16) H. I. Aaronson and C. E. Wells: Trans. AIME, 204 (1956), 1216.

17) C. J. McMahon and M. Cohen: Acta Met., 13 (1965), 591.

18) J. Gurland and J. Plateau: Trans. ASM, 56 (1963), 442.

19) P. G. Winchell and M. Cohen: Trans. ASM, 55 (1962), 347.

20) K. J. Irvine, F. B. Pickering, and J. Garstone: JISI, 190 (1960), 66 .

21) M. A. Grossmann: Iron Age, July 17, (1924).

22) M. J. Duggin and L. J. E. Hofer: Nature, 212 (1966), 248.

23) K.J. Jack and S. Wild: Nature, 212 (1966), 248.

24) Y. Ohmori and S. Sugisawa: Trans. JIM, 12 (1971), 170.

25) K. J. Irvine and F. B. Pickering: JISI, 190 (1960), 137. 